\title{
FY2020 April Monthly Status Report for the Versatile Test Reactor
}

\author{
Connie Stevens
}

May 2020

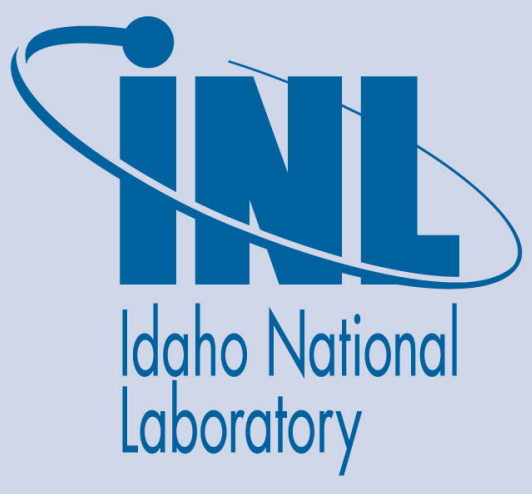

The INL is a U.S. Department of Energy National Laboratory operated by Battelle Energy Alliance 


\title{
FY2020 April Monthly Status Report for the Versatile Test Reactor
}

\author{
Connie Stevens
}

May 2020

Idaho National Laboratory Idaho Falls, Idaho 83415

http://www.inl.gov

Prepared for the

U.S. Department of Energy

Under DOE Idaho Operations Office

Contract DE-AC07-05ID14517 


\section{Mark Arenaz, Federal Project Director}

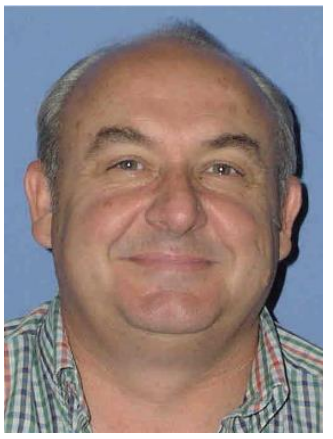

The VTR Team has done an incredible job getting ready for the Critical Decision (CD)-1 Project Management Risk Committee (PMRC)/pre-Energy System Acquisition Advisory Board (ESAAB) meeting in June. All project documentation is prepared with a few documents in the signature cycle at U.S. Department of Energy (DOE) Headquarters. The Conceptual Safety Design Report (CSDR) and Safety Design Strategy (SDS) have been signed and are ready to go as well. We are through about a sixth version of the PMRC presentation and are ready to send the presentation to Project Management (PM) for their suggestions and a dry-run. Moving forward! Keep up the good work.

\section{Jordi Roglans-Ribas, Program Overview}

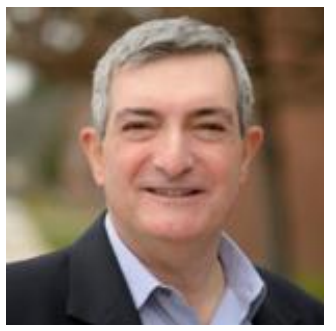

April brought significant change to the VTR Program with John Bumgardner's retirement. Though we are excited for the next exciting phase in John's life, his knowledge base and ability to lead a geographically-dispersed team will be greatly missed. Congratulations, John, and best wishes to you and your wife! With John's retirement, the search is underway to fill the VTR project manager position. Interviews will be held the first week of May. Until a replacement is identified, I have assumed the responsibilities of acting Project Manager and Thomas Fanning has been appointed VTR Nuclear Technical Integration Principal.

The program welcomes Kortny Rolston-Duce to lead VTR's communications and stakeholder engagement efforts. Kortny was most recently the Manager of Science Communications responsible for science and research communications and external communications functions at Idaho National Laboratory (INL). Kortny's duties include developing strategies to effectively communicate the need for VTR as a global asset in the development of advanced nuclear energy. She will also help build strong support among industry, government officials, and other key stakeholders.

The overall organization chart for the project is being updated to better transition the VTR Project Team from the conceptual design to the design-build phase of the project.

CD-1 documentation reviews that took place in February (Project Peer Review) and March (Independent Cost Review) were finalized in April. The VTR team provided factual accuracy comments on drafts of both reports. The review teams issued the reports in final form to be considered at the PMRC. To prepare for the PMRC, multiple discussions have occurred between DOE Office of Nuclear Energy (NE) and the National Nuclear Security Administration (NNSA) regarding fuel source material for the VTR.

The Request for Proposal (RFP) for the Design-Build contract was issued on April 1, and a pre-proposal conference was held with each prospective bidder. Completed proposals are due to be submitted to Battelle Energy Alliance (BEA) on June 1.

The entire team continues to work remotely. Initial telecommuting challenges experienced in March have been largely overcome during April and the team has worked efficiently in this mode. Upcoming major meetings, including the large experiment integration meeting scheduled in June, are being planned as on-line meetings. 


\section{Pat Schweiger, Reactor Technical Integration}

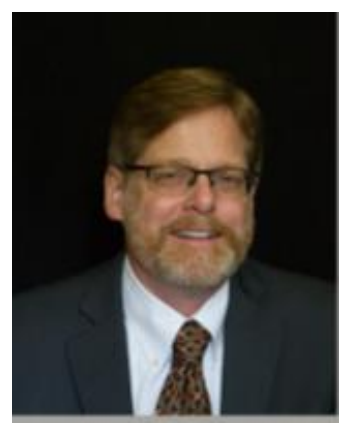

The following activities were supported during the month of April.

\section{VTR Conceptual Design}

Reviewed draft work packages to enable collaboration between France (French Alternative Energies and Atomic Energy Commission [CEA]) and the VTR Project and provided recommendations for the proposed tasks. Proposed an exchange of information by CEA on sodium fire experiments including large-scale sodium fire tests carried out in France in support of SUPERPHÉNIX.

\section{VTR Sodium Fire Analyses}

Reviewed data and formulated and applied a new phenomenological model to analyze the AB1 and AB2 tests involving sodium pool fires carried out at the Hanford Engineering Development Laboratory (HEDL) Containment Systems Test Facility (CSTF). The purpose was to attempt to identify a model that can reasonably predict the sodium burning rate per unit surface area for a sodium pool covering only a portion of the floor area inside a closed volume in which a recirculating flow pattern is expected to develop. Compared model calculations with reported values for the sodium burning rate per unit surface area at the beginning, middle, and end of the sodium pool fire. Prepared and distributed an informal report titled "Modeling, Calculations, and Comparisons with Data for the Sodium Pool Burning Rates per Unit Surface Area in the CSTF AB1 and AB2 Tests" to Argonne National Laboratory (ANL) staff for internal review. This material will be incorporated into a report on Verification and Validation (V\&V) of sodium fire models and computer codes. Prepared a V\&V table of sodium fire models and computer codes was prepared covering sodium fire assessment criteria/figures of merit, dependency on sodium fire mitigation design features, major phenomena determining the figures of merit, and dependencies of each major phenomenon upon lower level phenomena. ANL staff meet weekly to establish V\&V and software quality assurance (SQA) requirements for legacy sodium fire analysis codes.

Initiated a comparison of SOFIRE II code calculations versus data from the AB1 experiment conducted at HEDL involving a sodium pool fire inside of a closed $852 \mathrm{~m}^{3}$ carbon steel vessel.

\section{GE-Hitachi (GEH)/Bechtel National Incorporated (BNI) Design Engineering Support}

Conducting supply chain activities for equipment that requires prototyping and additional information regarding manufacturing to support ongoing refinement of the VTR cost estimate. Equipment includes the reactor vessel, in vessel transfer machine, intermediate heat exchanger, sodium-to-air heat exchanger (SAHX), electromagnetic pump, and control rod drive mechanism. This activity is expected to continue through the end of FY 2020.

Transmitted eleven documents to BEA for review, including updated VTR general arrangement drawings (nine total), containment structures, systems, and components (SSCs) boundaries and requirements document, equipment qualification specification, and mechanical separation document.

Continued refinement of the secondary heat transport system continued which was reflected in Revision C of the plant general arrangement drawings. The goal of the ongoing work is to reduce the volume of sodium needed to support heat rejection to the SAHXs and address fire protection concerns. Progress is proceeding well and is expected to continue through the end of FY 2020.

Validated VTR stakeholder requirements with BEA and updated the requirements management database. Continued building linkages between the stakeholder and system-level requirements. Refining requirements building linkages will prepare the project for preliminary design work and enable rapid impacts analysis of any future design or requirements changes on the existing design effort. 
Drafted the test assembly fabrication plan for core component mechanical tests which is being reviewed internally.

The VTR-specific Test Assembly Handing Machine (TAHM) grapple equipment was delivered to TerraPower Intellectual Ventures (IV) lab, shown in Figure 1. Due to IV lab access and Washington State restrictions, the dismantling and installation work was postponed.

\section{Fast Flux Test Facility (FFTF) Documentation and Data Recovery}

Retrieved and transmitted multiple FFTF Control Rod Design Documents requested by GEH to BEA including: the Royal Industries Life Design Report, the Royal Industries Life Test Report, the Westinghouse Advanced Reactors Division Life Environmental Life Test Report, the Final Test Report for the Hydraulic Balance Piston Rings, and the Review of the FFTF and Clinch River Breeder Reactor Plant (CRBRP) Control Rod System Designs.

Reviewed the production of Ar-41 and its management in the Radioactive Argon Processing System (RAPS) to answer emerging VTR questions. After reviewing this information and how it was handled at the FFTF, it was determined that three sources or production methods were accounted for: (1) neutron streaming from the core up through the sodium pool and through the

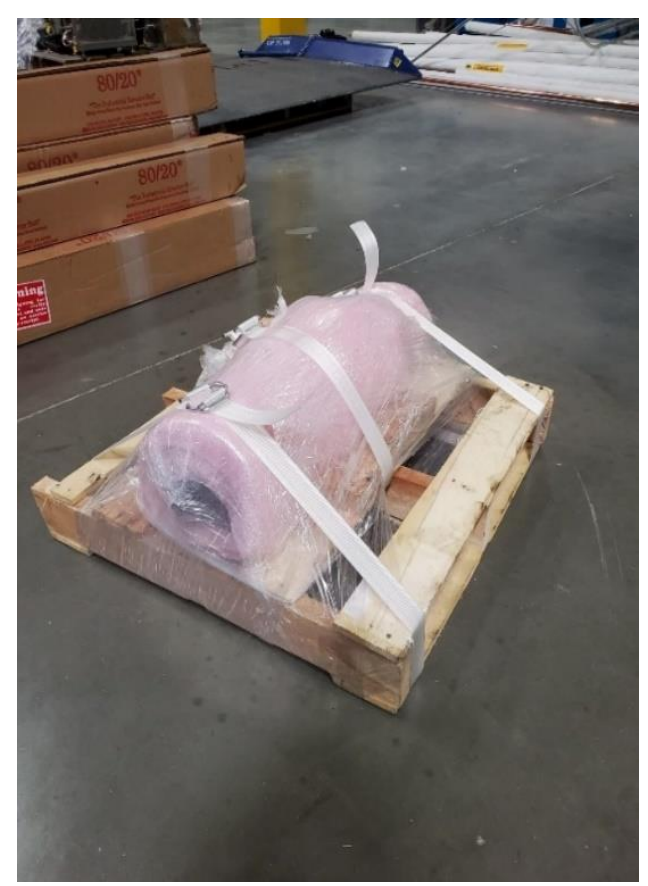

Figure 1. THAM Grapple Equipment. cover gas, producing Ar-41 by the (n, $\gamma$ ) reaction in Ar-40; (2) due to dissolved argon in the primary sodium caused by capture of the argon cover gas at the turbulent sodium and cover gas interface; and (3) by neutron capture in trace potassium impurities in the sodium via the $(n, p)$ reaction with K-41. Depending upon the amount of the trace potassium impurity, the $(n, p)$ reaction can be the largest source of Ar-41. It is important to note that any Ar-41 produced in the sodium in the core, regardless of the process, eventually moved up through the sodium pool to the cover gas for subsequent handling by the RAPS. Regardless of the source of Ar-41, it should be possible to design a equivalent RAPS system to hold it up for a sufficiently long period of time as the half-life of Ar-41 is only 1.8 hours.

Investigated input for the environmental impact statement (EIS) regarding anticipated personnel exposure rates at the VTR. Historical FFTF data from 1982, 1983, and 1984, indicate the average annual exposure per individual was 36, 11, and 37 millirem, respectively.

Located and retrieved a dozen reports describing tests on sodium fires conducted in the Sodium Fire Test Facility on the Hanford Site. These reports describe the results of different tests such as pool fires, trench fires, and spray fires. As soon as access to the Lab buildings and spaces is available, the reports, along with a summary report, will be submitted through Export Control and Information Release processes.

\section{VTR Control Rod Mechanical Design Analysis}

Located and retrieved drawings describing significant mechanical features of the FFTF control rod design. These features are related to the ability of the control rods to perform their mechanical translation function in the core. Have developed a list of open questions of interest related to the mechanical design of the VTR control rods and the questions will be discussed with ANL reactor physics staff as soon as access to the Lab buildings and spaces is available.

The computer codes used to ensure proper performance of the FFTF control rod absorber bundles are now operational. The three codes are CRBRP, CRPBOW, and SCRAM, which were operational codes during FFTF operation and therefore had embedded FFTF parameters. An effort to remove these parameters and make them input data is underway, which will allow the codes to support the design of the VTR during the advanced conceptual design. 
Calculation Support for VTR Waste Form Analysis

Identified an initial concept for the waste form and design requirements for storage and transportation. Developed and submitted a draft description document for a VTR dry fuel storage design to BEA for review and comment. Next, a preconceptual design and scoping thermal analyses will be generated to demonstrate the feasibility of the canister-based storage system for the VTR fuel.

\section{Tom Fanning, Nuclear Technical Integration}

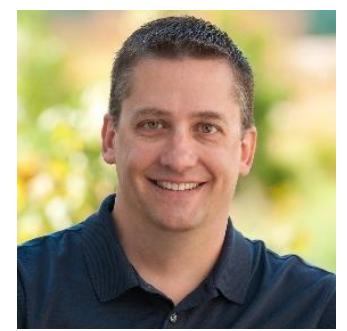

The Nuclear Technical Integration area includes the coordination of activities related to the design and safety analysis of the VTR reactor core and fuel. In the month of April, the Nuclear Technical Integration area continues to support all CD-1 activities.

\section{Fuel}

Drafted a VTR U-Pu-ZR fuel slug specification and circulated the specification for initial review. When issued, this specification, and its subsequent revisions, will guide acceptance of VTR U$\mathrm{Pu}-\mathrm{Zr}$ driver fuel slugs. Initial thermal-mechanical performance models of fuel slug shape imperfections, such as out of round or straightness deviations, validate the draft manufacturing specifications. The supplemental analyses also offer opportunities for additional dimensional tolerancing detail to support greater manufacturing flexibility. Continuing the preparation of VTR Fuel Performance Design Basis Rev. 1. In addition, completed and documented a detailed study on plutonium supply issues and available options. Prepared and submitted plutonium compositions representing three types of sources to the VTR EIS contractor.

TerraPower completed procurement specifications for HT9 cladding and ducts. These specifications will be used to survey potential HT9 material, cladding, and duct suppliers regarding ability and price for supplying VTR assembly structural materials. Savannah River National Laboratory (SRNL) continued advanced conceptual design work on plutonium processing equipment layout.

Completed a preliminary fuel performance assessment of VTR driver fuel using BISON for normal and off-normal operations. Drafted a report which is now going through internal review at Oak Ridge National Laboratory (ORNL). In support of VTR fuel performance analysis, the IFR-1 BISON benchmark model is now documented and in internal review. Continuing work using sensitivity analysis tools to look at the impact of several input parameters on key results in the IFR-1 and X430 benchmark models.

Continuing progress on an advanced conceptual design of the fuel manufacturing equipment. Completed a design review for the demolding glovebox and associated equipment, covering material process flows and equipment designs with detail sufficient to produce a request for quotation (RFQ) for final design and procurement. Documented design details, as well as historical manufacturing details that were leveraged in the design, in a technical evaluation. Completed the functional and operational requirements (FOR) document for the scrap and waste processing glovebox and equipment. Lastly, completed a design review and FOR for a general-purpose Pu processing glovebox that can accommodate the VTR fuel casting system, if needed.

\section{Core Design}

The validation activities for the neutronics codes reached a major stepping-stone with the completion of the analyses based on the Zero Power Reactor (ZPR)/Zero Power Physics Reactor (ZPPR) experiments applicable to VTR. No impactful shortcoming was found in the analysis capabilities used for the VTR. These results are summarized in a validation report. The next validation steps will consider the data pertaining to FFTF and Experimental Breeder Reactor (EBR)-II as a source of additional validation problems, primarily related to fuel burnup and void worth validation. In addition, completed Monte Carlo N-Particle (MCNP)-based confirmatory analyses which documents pin-by-pin depletion and rod-worth results. 
The VTR design team performed several quick turn-around calculations and assessments to document the impacts of using low-enriched uranium (LEU)-based fuel rather than plutonium-based fuel. Results of the analyses indicate three times as much fuel would be required (with LEU), more control rods would be needed, passively safe behavior of the core could be impaired, and design uncertainties would be more impactful on the design margins.

Began procurement for equipment for the pressure drop experiment planned for this fiscal year. Work performed using computational fluid dynamics (CFD) analysis focused on parametric studies of the sodium flow in different geometries. Radii of $10 \mathrm{~mm}$ are sufficient to significantly reduce the impact of sharp edges for impinging surfaces, and the edge radii of originating surfaces has no major impact of the pressure drop observed. Some results are shown in Figure 2. This is laying the basis for designing assemblies to minimize the primary system pressure drop and therefore gain more thermal-hydraulic margins.

\section{Safety Analysis}

The Safety Analysis team implemented a reactor protection system (RPS) model in SAS that was assumed for the VTR safety analyses used in the CSDR. The RPS model monitors power, power-to-flow ratio, core inlet temperature, and core outlet temperature to determine when a reactor trip is necessary and when control rod scram, pump trip, and SAHX trip are necessary. Additional sensors have been added for other process parameters to support monitoring power rates for very low power transients.

Performed modeling and analysis of a series of postulated overcooling events to better understand how various scenarios will progress and what sort of monitoring and/or response

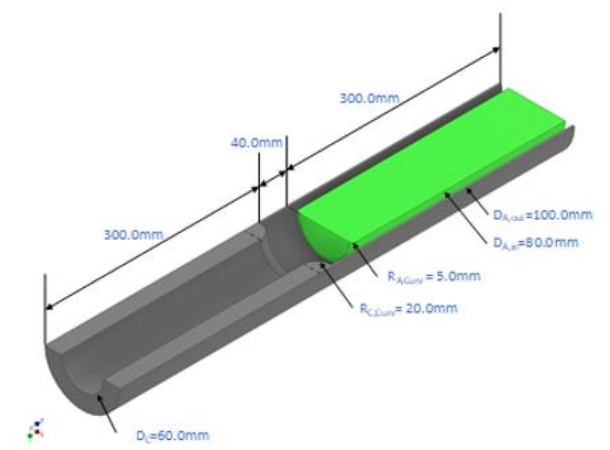
measures might be utilized, possibly including actions by the reactor control system, by reactor operators, or even no action.

Completed a wide range of simulations to determine VTR response to a range of reactivity insertion rates during control rod withdrawal. Results of this analysis will help inform control-rod driveline (CRDL) speed controls.

Continuing work on a simplified eutectic penetration correlation to support VTR metallic fuel transient calculations. This will help provide better fuel and cladding composition dependent eutectic penetration data rather than using the composition independent correlations currently implemented in SAS.

\section{Safety Basis and Probabilistic Risk Assessment (PRA)}

The VTR Alternate Methodology Request for the Documented Safety Analysis was approved by DOE on April 7 , providing official DOE approval of the VTR approach to developing the required final safety basis documents. It is an optimized approach for integrating the appropriate regulatory requirements and analysis methods in a manner that is appropriate for the safety by design features included in the VTR. The approved methodology will support the VTR goal of safety by maximizing the passive safety and simplicity of design features wherever practical.

In a significant achievement, the VTR Conceptual Safety Design Report (Rev. 0), Safety Design Strategy (Rev. 1), and Probabilistic Risk Assessment Plan were approved by DOE on April 30 via a Safety Review Letter. These approvals signify completion of all required safety documents necessary to support the CD-1 package. 
Safety Analysis Software Quality Assurance (QA) activities - Confirmatory Analysis

Completed QA of the Reactor Vessel Auxiliary Cooling System (RVACS) models in SAS, and the final report (ECAR) is undergoing final review. Activities are now moving toward verification of thermal calculations which support reactivity feedback modeling, specifically for CRDL expansion in the upper internal structure (UIS) and radial expansion for the detailed radial expansion feedback model. Constructing a SAS model of the MCTF PRISM mockup to support validation of low-flow thermal hydraulic phenomena. Obtained preliminary results for CRDL expansion verification, primarily with respect to UIS and CRDL temperature calculations. Results are undergoing additional review to confirm acceptance.

To support confirmatory analysis, an independent model for the VTR is being developed using the U.S. Nuclear Regulatory Commission (NRC) TRACE code. Sodium equation-of-state models were developed by the Paul Sherrer Institute (PSI), and code fixes needed to be developed by the NRC to eliminate convergence issues at sodium-gas interfaces. Currently, a steady-state model has been executed and steady-state results have been compared with the SAS steady-state values. A difference in the primary coolant temperature is observed due to the expected difference in the heat transfer models used in the heat exchanger.

\section{Kevan Weaver, Experiments Technical Integration}

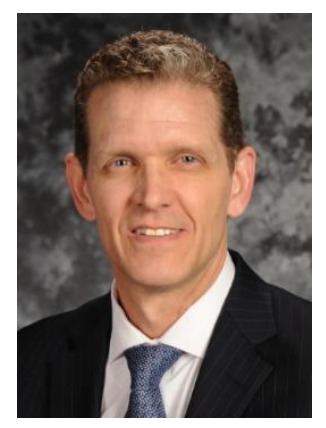

The Experiments Team within the VTR program includes nine "functional" areas aligned with the experiment vehicle types, along with related capabilities and initiatives, anticipated to be utilized within the VTR. Each area is led by a national laboratory technical expert and is supported by other national laboratory personnel, university partners, and industry partners.

Selected key accomplishments within specific functional areas are included below.

\section{Sodium Loop Capability Development}

Technical Lead: Mitch Farmer, ANL

Partners: University of Wisconsin, Purdue, Framatome

ANL began telecommuting due to the Coronavirus Disease (COVID)-19 on March 17, and the laboratory space was shut down all of April. Continued to provide support in the development of a pre-conceptual sodium cartridge test loop. The cartridge transient analysis tool, CARLITA, is scheduled for release in early May.

\section{Lead/Lead Bismuth Loop Capability Development \\ Technical Lead: Cetin Unal, LANL \\ Partners: University of New Mexico, Westinghouse}

Develop a Pre-conceptual Design for a Pb/Pb-Bi Reactor Cartridge Test Loop. Further developing the mechanical pump option for a detailed design specification, and the secondary pump option is mechanical with gas-lift. The updated design leverages commercially available standard pipe sizes to save cost and reduce customized components in the $\mathrm{Pb}$ loop fabrication. Implemented the updated $\mathrm{Pb}$-loop dimensions into the TRACE-Pb code for system analysis and for steady and transient cases.

Design and Testing of Centrifugal Pump for a Lead Cartridge Loop. Depending on analysis progress, and on back-towork dates, the pump may be printed and tested without completing the analysis and modifications. Also, a test stand for water pump tests is in progress.

Irradiation Data Needs and Lead Cartridge Requirements and Interfaces. Continuing development of requirements, implementing comments from the team, and new requirements will be added based on VTR team interactions.

Technology Readiness Assessment and Gap Analysis of Instrumentation for Monitoring Lead Cartridge Performance. For the liquid lead temperature, research concluded that the challenges associated with temperature sensor drift and calibration are well understood across the industry; therefore, research and development efforts specific to the lead 
cartridge loop are not recommended. For neutron flux, the high temperature environment creates significant challenges. No suitable neutron flux measurement technology is commercially available that functions at temperatures above $550^{\circ} \mathrm{C}$. The cartridge experiment variables to be investigated next are:

- Liquid lead flow rate,

○ Liquid lead oxygen content,

- Liquid lead composition,

○ Cover gas composition (including fission gasses and $\mathrm{He}$ ),

- Cover gas pressure.

Identification of Enabling Technologies for Longer Life and Higher Temperature Cartridges. Creating a draft report utilizing materials performance data gathered from the literature under previous Westinghouse efforts. This report focuses on how materials performance improvement strategies for the VTR Pb cartridge can be applied to an engineering structure. Particularly this will seek to leverage coating or cladding technology to mitigate corrosion of the VTR Pb cartridge while allowing the use of commercially available and ASME code qualified engineering materials. To support this focus, materials suppliers and fabricators are being contacted regarding processes relevant at the size scale of the VTR Pb cartridge.

Pump Optioneering Study for the VTR Pb Cartridge. Identification and weighting of criteria for use in cartridge pump decision analysis has further materialized, including criteria pertaining to normal operating conditions, off-normal operating conditions, and component reliability in the context of a high temperature liquid metal environment.

Corrosion and Erosion Studies of Selected Clad and Structural Materials. The 32 specimens tested in March 2020 were not analyzed due to the COVID-19 shutdown; however, corrosion experiments were able to restart the last week of April.

Stagnant corrosion tests. Due to access restrictions, the tests have not started.

\section{Molten Salt Loop Capability Development \\ Technical Lead: Joel McDuffee, ORNL \\ Partners: University of Utah, University of Idaho, MIT, TerraPower}

Thermosyphon Test Loop (annular flow characterization). Wrote a journal paper titled Single-phase, natural circulation annular flow measurements for cartridge loop irradiation experiments which will be submitted for internal review. The paper provides critical experimental data for validation of thermal hydraulics models of natural circulation flow in annular geometries representative of expected VTR cartridge experiments. Non-dimensional analyses indicate that natural circulation flow can provide liquid salt Reynolds numbers similar to those of some molten salt reactor concepts at relevant power densities.

A purchase order for Phase 2 modification of the thermosyphon test loop was awarded, which will incorporate the full size in-core section of a VTR experiment, pumped flow, and a molten salt surrogate internal coolant.

Corrosion Sensor Development. Received comments on a journal paper titled Metal-embedded fiber optic sensor packaging and signal demodulation scheme towards high-frequency dynamic measurements in harsh environments. The sensing system developed in this paper is being used to monitor diaphragm deflections during active pressurization of the VTR corrosion sensor. Also demonstrated that the control system is capable of automatically producing a steady output pressure and has interfaced with the prototype corrosion sensor for additional testing and characterization prior to corrosion tests.

Cartidge Loop Structural Materials Assessment. Conducted a brief investigation and the best options are: 
- Hastelloy $\mathrm{N}$ sets the upper temperature limit at $700^{\circ} \mathrm{C}$ for steady-state temperatures due to high-temperature embrittlement concern, and possibly up to $800^{\circ} \mathrm{C}$ under accident/safety conditions. Additional assessment will be required to understand possible DPA limits, fatigue cycle limits, etc.

○ Incoloy $800 \mathrm{H}$ with liner.

○ SS316.

2D Thermomechanical Modelling of Cartridge Loop. A thermomechanical script was created which implements a 2D model in Abaqus (finite element model), shown in Figure 3.

Salt Selection and Properties. Reviewed candidate salt systems and selected the $67 \mathrm{~mol} \% \mathrm{NaCl}-33 \mathrm{~mol}_{\%} \mathrm{UCl}_{3}$ eutectic as the base-line salt to use for this round of calculations to support iterations on the vehicle design.

ARMI Updates, Material Model Updates, and Gamma Heating $\underline{\text { Analysis }}$

○ Updated VTR-EV neutronics model to run with ARMI Version 7.

- Updated to VTR geometry based on ECAR-4647.

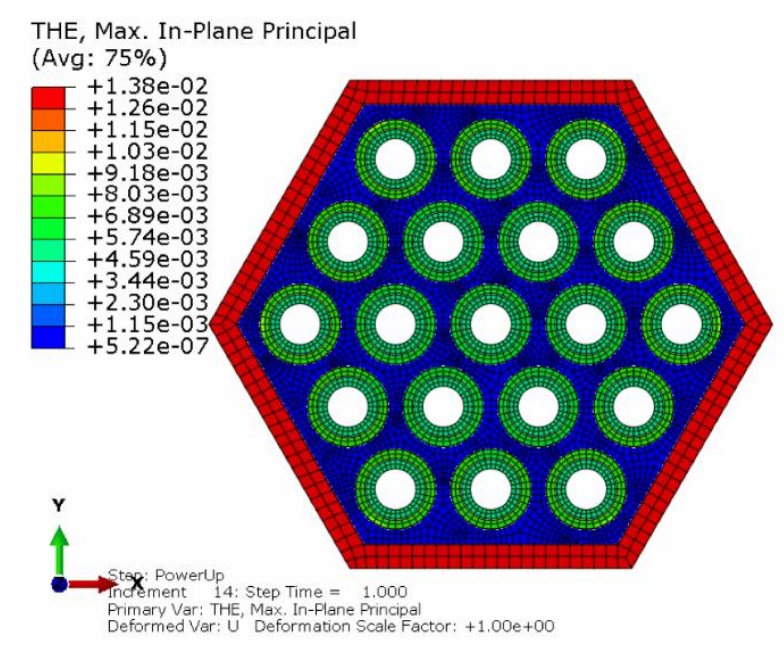

Figure 3. 2D model in Abaqus.

○ Updated mass fractions and added thermal expansion for Hastelloy-N and Incoloy 800 materials.

- Performed analysis to separate gamma heating and deposited neutrons from each component (salt/sodium/structural).

○ Ran several ARMI cases to compare gamma heating of structural materials

- Cases modeling structural material as Inconel 800 and SS316.

- Ran cases modeling Fuel Temperature at 600 and $800^{\circ} \mathrm{C}$ in addition to the baseline $700^{\circ} \mathrm{C}$.

○ Planning began for modeling VTR-EV with sodium reflectors in test position for 6 cycles.

- This modeling matches the modeling approach described in ECAR-4647.

- There will be a comparison of the flux of above model run to that reported in VTR documentation for a better understanding with how closely models match.

- Several plots were generated depicting the power, burnup, gamma heating, flux, and dpa of the VTR core for potential test locations for several design variations.

Electrical Heating Scoping. For standard band heaters/heat tape, found that wrapping the entire loop only yields a maximum of around $4 \mathrm{~kW}$ of heating - considerably short of the required heating capacity. Also, current assumptions place the required amount of heating capacity for the vehicle approximately $10 \mathrm{~kW}$ during outage conditions.

Tube and Shell Optimization for Cartridge Loop. The following updates to the model were made:

- A hex-can was built on the heat exchanger side which greatly improved the hydraulics and the cooling efficiency. 


\section{FY2020 April Status}

\section{Versatile Test Reactor}

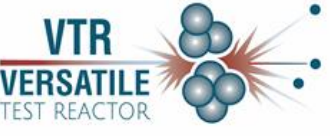

- Focused on forced convection, running different pump characteristics to evaluate the impact on flow and temperatures based on requirements.

○ The design provides good results and low temperatures under forced flow conditions.

- Able to remove approximately $90 \mathrm{~kW}$ of power generated inside the salt.

- Natural circulation remains to be evaluated as well as optimizing the size of the hot leg.

- Updated the powers, separating heating power due to gamma heating into the structure from the fission and gamma heating power applied in the salt.

- Results show that $20 \%$ enrichment with forced flow configuration is achievable in terms of temperatures inside the loop.

- Design shows to have flexibility in terms of velocity as well as power applied depending on the target.

\section{Annular Design Updates.}

- A preliminary look at the 37 tube heat exchanger design showed the following:

- Preliminary thermal scoping shows an improvement of the salt power being rejected.

- An increase in structure will also increase the gamma heating.

- Performed a preliminary study for placement inside a VTR duct comparing 37-tube vs. 19-tube tube-inshell heat exchanger options, shown in Figure 4.

○ Completed work on sizing the annular design.

- The proposed concept remains shifted high enough axially in the core to promote natural circulation, if needed.

- Maintained a reasonable pressure drop by maximizing the width of the hot and cold legs.

- A significant amount of salt needs to be displaced from the center of the hot leg to balance the heat rejection capability of the cold leg.

- A central post is proposed as the displacing volume, which can be used to place a heating element in the hot leg to help keep the salt molten during outages.

- The pump is envisioned to be placed at the top of the hot leg.
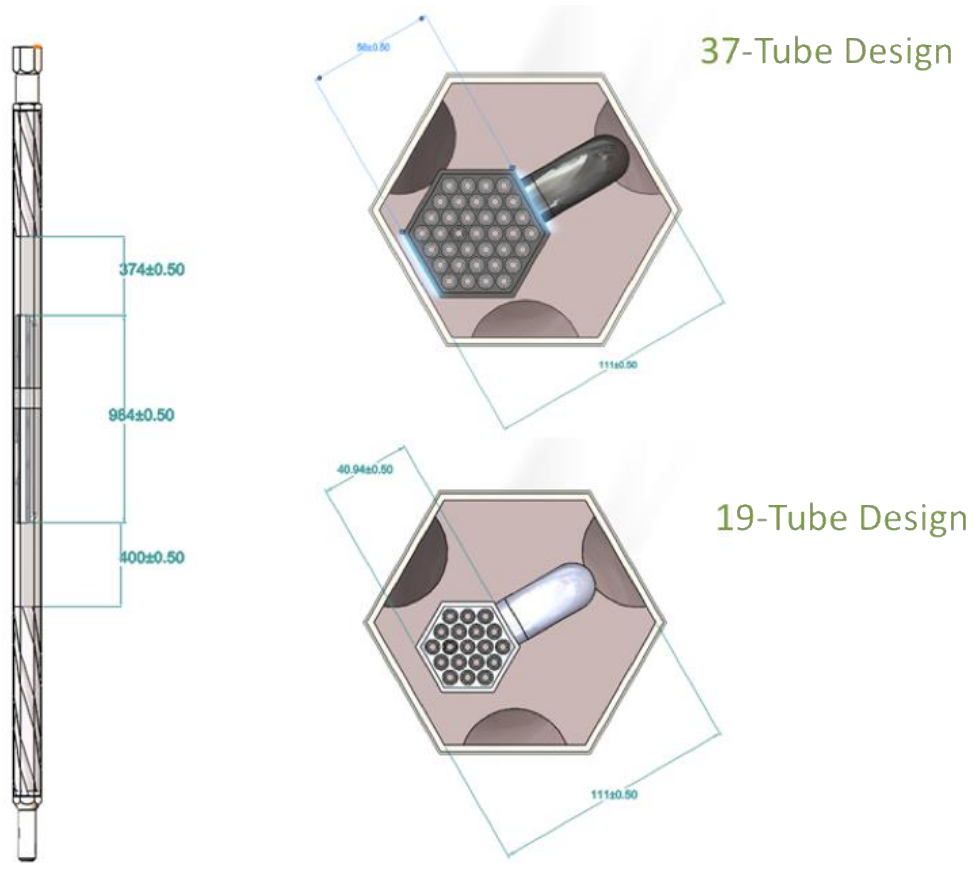

Figure 4. Comparison of 37-tube vs. 19-tube, tub-in-shell heat exchanger.

○ Initial calculations show that approximately $65 \mathrm{~kW}$ of cooling capacity is feasible with this design.

○ Performing updated power calculations to evaluate thermal performance of the system. 


\section{FY2020 April Status}

Rabbit System Capability Development

Technical Lead: David Wootan, PNNL

Partners: Texas A\&M University (TAMU)

TAMU continued to work on in-situ sensors, neutronic streaming, thermo-hydraulic, and mechanical aspects of the Rabbit.

The schedule for putting the Rabbit Proof-of- Principle Test into the water pool at the TAMU TRIGA reactor is delayed at least one month (until June 20) due to COVID-19 work restrictions put in place by the Governor of Texas and the Texas A\&M University President.

Instrumentation and Controls

Technical Lead: Sacit Cetiner, ORNL

Partners: ACU, Georgia Tech, MIT, University of Pittsburgh, Cosylab

Finalized the scope of work for new industry partner CosyLab.

Drafted a journal article documenting the Eddy-Current Flow Meter work completed during the last year.

Updated the Self-Powered Neutron Detector code to the latest version of Geant 4 and modified the Geant 4 activation example to run with vanadium to validate physics.

Digital Engineering + Virtual Design and Construction

Technical Lead: Chris Ritter, INL

Partners: North Carolina State University, Colorado School of Mines, Virginia Commonwealth University, (VCU), TerraPower

TerraPower has a 15-cycle VTR ARMI input deck running with fuel management that gets up to about 10\% FIMA to run BISON demo runs on. This is not on the latest VTR model but should be sufficiently close to demonstrate meaningful usage of the tools together. The team ran initial cases transferring ANL physics code output into the BISON template for the VTR case. TerraPower continued to investigate and update the BISON input template and look at the output as we learn how to get the output we need out of BISON to be applied back to the ARMI state. It is understood that this project is intended to just show bi-directional data flow between ARMI and BISON, not necessarily to perform design analysis.

VCU/TAMU have improved the acquisition of requirements data from DOORS by automating the retrieval of module requirements data. A script was created that is able to track the changes made in individual module requirements over time, showing the sub requirements added and removed from a module. This will allow users to have version control for the modules. Also, the extension widget for Jazz was improved to enable removing font sizes and font families from all the sub requirements in a module.

\section{Upcoming Events:}

June 1, 2020, Deadline to submit design-build proposals

June 2, 2020, Project Management Risk Committee meeting

June 2 - 3, 2020, Experiment Integration meeting

June 8 - 11, 2020, American Nuclear Society meeting

June 23 - 24, 2020, VTR Quarterly Integration meeting 